\title{
Using a disciplinary discourse lens to explore how representations afford meaning making in a typical wave physics course
}

\author{
Margareta Enghag, Jonas Forsman, Cedric Linder, Allan Mackinnon and Ellen Moons
}

\begin{abstract}
We carried out a case study in a wave physics course at a Swedish university in order to investigate the relations between the representations used in the lessons and the experience of meaning making in interview-discussions. The grounding of these interview-discussions also included obtaining a rich description of the lesson environment in terms of the communicative approaches used and the students' preferences for modes of representations that best enable meaning making. The background for this grounding was the first two lessons of a 5 -week course on wave physics (70 students). The data collection for both the grounding and the principal research questions consisted of video recordings from the first two lessons: a student questionnaire of student preferences for representations (given before and after the course) and video-recorded interview-discussions with students (seven pairs and one on their own). The results characterize the use of communicative approaches, what modes of representation were used in the lectures, and the trend in what representations students' preferred for meaning making, all in order to illustrate how students engage with these representations with respect to their experienced meaning making. Interesting aspects that emerged from the study are discussed in terms of how representations do not, in themselves, necessarily enable a range of meaning making; that meaning making from representations is critically related to how the representations get situated in the learning environment; and how constellations of modes of disciplinary discourse may be necessary but not always sufficient. Finally, pedagogical comments and further research possibilities are presented.
\end{abstract}

\section{Introduction}

Over the past 20 years, much research-based effort has gone into looking for effective ways to improve the teaching and learning of university physics. Perhaps the most powerful dynamic that a teacher can introduce into their classroom to enhance learning outcomes is one where students engage with one another in small groups as part of a broader teacher- student engagement (for example, see Deslauriers, Schelew \& Wieman, 2011; Mazur, 2009; and for an in-depth review of "promising practices in undergraduate science," see Froyd, 2008). The development of teaching practice informed by active engagement (for example, see Mazur, 1997; Van Heuvelen \& Etkina, 2006) requires a new awareness of the role that representations-the highly specialized 
forms of communication used in science-play in the affordance of learning (Van Heuvelen, 1991). Even though a large number of prominent science educators have convincingly argued that many of the challenges found in science learning are largely a function of difficulties in handling and understanding such representa- tions (Erickson, 2007), relatively little research has focused on this issue in university physics. To investigate the relations between the representa- tions used in university lessons and the experience of afforded meaning making, we carried out a case study in a wave physics course at a well- respected university in Sweden. In this case study, we focused on how a particular set of representations facilitated meaning making in small- group discussions. These small-group discussions were formulated in an interview-discussion environment outside of class. We did this as a way to create the kind of peer discussion that physics education research calls for in order to establish effective interactive engagement (Mazur, 2007). To establish a grounding for the design of our interviewdiscussion environment for the case study, we obtained a profile of the classroom engagement that the participating students were experiencing at that time in their actual lessons.

\section{Research aim}

Our research aim was to use a contemporary disciplinary discourse lens to explore how representations can afford meaning making in undergraduate physics. We used the form and content of a typical wave physics course as a way to ground the investigation. Thus, we formulated four research questions, the first three being aimed at establishing the required grounding for the fourth, the principal research question.

\section{Grounding Research Questions}

For the first two lessons (lectures) of a selected typical wave physics course:

1. What communicative approaches were used?

2. What modes of representation were used?

3. What was the trend in students' views of different representations are preferable for meaning making?

\section{Principal Research Question}

(d) How did the students discuss the representations in relation to making meaning from some of the basic building block concepts for the course?

\section{Theoretical background}

Meaning Making Physics is a body of theory and models developed for making meaning (i.e. understanding, explaining) of nature. To learn physics, a student needs to encounter physical objects, phenomena, and ideas. According to Blumer (1969/1986), students engage with these aspects in terms of the meaning they make from them. Blumer describes his three premises for meaning making. First, there is a self-interactive process, when students consider what experiences they already have which can give meaning to the situation (premise 1). The meanings are derived from, or arise out of, the social action one has with others (premise 2). Through this interaction and communication, meanings of encounters are derived and modified through an interpretative process (premise 3). When students learn physics, they encounter many representations of surrounding physical phenomena. A student initially makes meaning through self-interaction and 
reflection on his or her own experiences by connection to the phenomena at hand (Dewey, 1938, 1997; Enghag, Gustafsson \& Jonsson, 2007). During teaching, both the teacher and student peers are used by learners to find meaning in what they experience during the lesson.

\section{Communicative approaches to make meaning}

Mortimer \& Scott (2003) described how teachers use different communicative approaches in the interaction with the students. They constructed a two-dimensional model about communication in the classroom: Within the two dimensions, interactive/non-interactive, and authoritative/dialogic, there are four categories of communicative approaches (see Figure 1).

Students also learn from each other if they get given opportunities to meet and discuss (see Hake, 1998; Blumer, 1969/1986; Mercer, 1995). Sometimes this only becomes possible outside the organized activities. However, if small groups are used within the class, student-student communication is vital for enhancing learning outcomes (Mazur, 2009).

\begin{tabular}{l|l|l|}
\hline $\begin{array}{l}\text { Focus on science view } \\
\text { (Authoritative) }\end{array}$ & $\begin{array}{l}\text { Interactive } \\
\text { Presentation } \\
\text { Question \& } \\
\text { Answers }\end{array}$ & $\begin{array}{l}\text { Presentation } \\
\text { Tecture }\end{array}$ \\
$\begin{array}{l}\text { Taking account of } \\
\text { students } \\
\text { understanding } \\
\text { (Dialogic) }\end{array}$ & $\begin{array}{l}\text { Probing } \\
\text { Elaborating } \\
\text { Supporting }\end{array}$ & Review \\
\hline
\end{tabular}

Figure 1. Communicative approaches (adapted from Mortimer \& Scott, 2003)

Gautreau \& Novemsky (1997) report that they have used "Overview, case study physics" (Van Heuvelen, 1991) for many years with very good results; they have noticed that a second teaching takes place in small group work after the teachers first teaching. This second teaching corresponds to an interactive-dialogic communication between peers, also referred to in the literature as "exploratory talks." In exploratory talks, the students take control of their learning activity, with students drawing one another into the discussion (Barnes, 1977; Barnes \& Todd, 1995; Mercer, 1995, 2000).

\section{Modes of representation}

Using a fine-grained interview approach, Kohl \& Finkelstein (2006) investigated relations between student problem-solving performances and how problem representations (verbal, mathematical, graphical, or pictorial) related to problem-solving competency. They found that student performance depended on particular combinations of representation and prior knowledge. They also found that students have robust opinions of their representational skills that correlate well with their performances. This is where our study focuses-at the junction of students' prior understandings/experiences and the representations used for a wave physics course. 
Airey \& Linder (2009, p. 28) define disciplinary discourse as the "complex of representations, tools and activities of a discipline." They use their modeling of disciplinary discourse (see Figure 2) and the related meaning making of disciplinary representations (Airey \& Linder, 2009, Figures 3-6, pp. 31-33) to develop a "generative metaphor" (Schön, 1978) of "discursive fluency" in relation to modes of representation:

By discursive fluency we mean a process through which handling a mode of disciplinary discourse with respect to a given disciplinary way of knowing in a given context becomes unproblematic, almost second-nature. Thus, in our characterization, if a person is said to be discursively fluent in a particular mode, then they come to understand the ways in which the discipline generally uses that mode when representing a particular way of knowing (Airey \& Linder, 2009, p. 33).

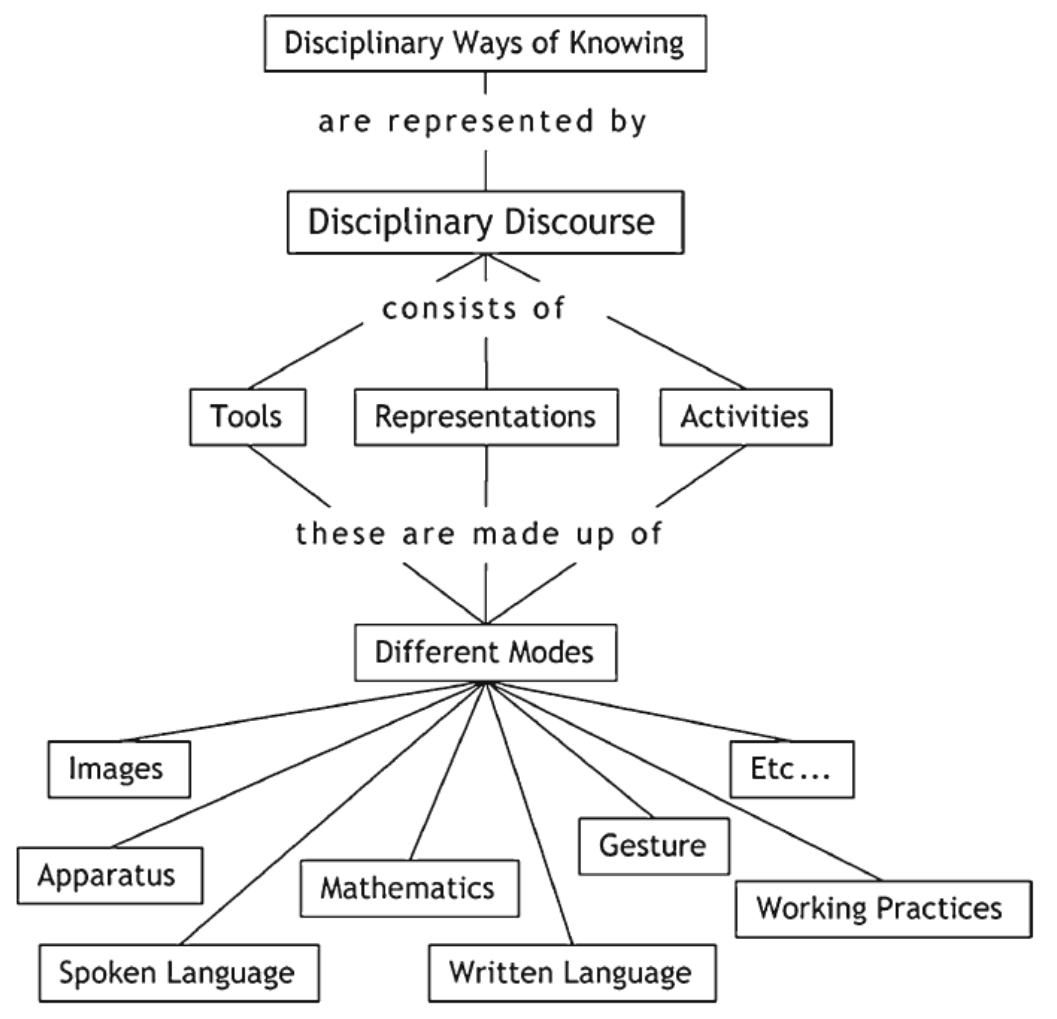

Figure 2. From Airey \& Linder (2009, p. 29, Figure 1) Diagram of the relationship between disciplinary ways of knowing and the modes of disciplinary discourse. These modes are essentially a form of semiotic resource (Airey, 2009)

Kress, Jewitt, Ogborn \& Tsatsarelis (2001) argue that disciplinary discourse is constituted from a wide range of modes and in doing so suggest that each mode will present different affordances to meaning making. They write:

Several issues open out from this starting-point: if there are a number of distinct modes in operation at the same time (in our description and analysis we focus on speech, image, gesture, action with models, writing, etc.), then the first question is: 'Do they offer differing possibilities for representing?' For ourselves we put that question in these terms: 'What are the affordances of each mode used in the science classroom; what are the potentials and limitations for representing of each mode?'; and, 'Are the modes 
specialized to function in particular ways. Is speech say, best for this, and image best for that?' (Kress et al., 2001, p. 1)

For our study, Bakhtin (1930, 1981, 2010) provides the link between the meaning making and the representations used in disciplinary discourse. Bakhtin does this through his description of how we live with the primary discourse of everyday life and how we need to grasp the secondary discourse with all its representations when we meet new environments and ideas.

\section{Research context and methods}

Ethics, Participants, and Classroom Environment Following the Swedish Research Council ethical guidelines, our aims and the associated ethical considerations were presented to an experienced and highly regarded physics teacher and the 70 students who participated in our study. They agreed to let us follow their wave physics course. The student body was made up of physics majors, engineering students, and physics teacherstudents. For all the students, this wave physics course was their second physics course. The classmet for lessons (lectures) consisting of $2 \mathrm{~h}$ a week for 5 weeks and for four problem-solving sessions (which were not part of our study). The other aspects of the classroom environment are described by the answers to the grounding research questions.

\section{Lesson content}

The course used the university physics textbook Physics for scientists and engineers (Knight, 2004), and the teacher used inter alia illustrations from this book as supportive teaching material. All material was presented via a computer driven projector. The textbook (Chapter 20: Travelling waves) deals with the following topics: The wave model, One-dimensional waves, The sinusoidal waves, Waves in two and three dimensions, Power and intensity, and The Doppler effect. We gave special attention to the two first lessons in this course, which dealt with the contents of Chapter 20, and it is from these lessons that we report on our data collection and analyses.

\section{Data collection and analytic method}

The grounding for the analyses came from two sources. We drew on Mortimer \& Scott (2003) regarding what communicative approaches were used. For the experience of representations and their meaning making potentials, we drew on the Airey \& Linder (2009) description of disciplinary modes (outlined in Figure 2) in relation to their notion of achieving discursive fluency that we described earlier. We used the way Airey and Linder characterized representation modes for a scientific discipline such as physics as an exemplar for how to create the modes we needed for our analytic purposes. For example, we took theirmode of Spoken Language and created three modes: Teacher Talk, Peer Talk, and Management Talk. Even though all of these could be categorized in a Spoken Language category, in the classroom context, we argued that it made good analytic sense for the purposes of our study to separate them in the way described. In the classroom, Teacher Talk is often used in conjunction with all other modes, so in categorizing the modality used to underpin the representations used we decided to exclude Teacher Talk as a separate analytic mode in this part of the analysis. However, the students' 
preferences and ranking of representations and communication did include the category Teacher Talk as a separate mode experienced by the students:

1. Video recordings: The video recordings of the lectures were made (two cameras: one that filmed the teaching activity from the students' viewing point and one that filmed the lesson activity from the teacher's viewing point). The videos were analyzed with time as one of the units of analyses. Time categorization was done in video-graph format using a video-analyzing computer program, VideoGraph (Rimmele, 2002). This was done in two simultaneously complimentary ways: first, to bring out the teacher's communicative approaches that were used and, second, to bring out the representations used (video recordings were of the full first two lectures).

The video was used to categorize the activities and representations used. The categories were formulated and then refined using the standard qualitative analysis iteration and saturation technique. The communication approaches and representation categories that were developed were independently verified by two of the authors with more than an 80 $\%$ interrater reliability (Stemler, 2004). As very few pictures were used, the original Pictures category was incorporated into the Diagram and Graphs category. The Teacher Talk category was divided into two because it included some extensive Management Talk.

2. A student questionnaire on representations: A questionnaire that asked the students to rank their preferences for representations and also general interaction was given before the first lecture and after the last lecture. We did this knowing that, due to the ethical constraints that we needed to work with (guaranteed anonymity), we would be unable to account for student attrition. However, our aim was to capture the nature of the general trend of representation preference, which we argue is possible without student identification. The students' ranking of representations provided us with information about the trends in meaning making that the students had experienced.

To bring out the trends, we performed an ANOVA Friedman test (cf. Siegel \& Castellan, 1988). This is a non-parametric test for testing the differences between several related samples.

The questionnaire was based on the Airey \& Linder (2009) model of how disciplinary discourse is built up from representations to share disciplinary knowledge. It spanned different modes of representation and also included communication and meaning making items drawn from the work of Mortimer \& Scott (e.g. 2003-talking to the teacher in dialog) and from the work of Blumer (e.g. 1969-talking with peers for meaning making). We posit that this theoretical framing provided a good validity for the content of the questionnaire. The judges of good reliability come from the several small trials of the questionnaire followed by rigorous discussions amongst the authors.

The questionnaire consisted of the items (translated from Swedish) given below. These items were linked to a response sheet with a scale of $1-6$ (1 being most important, 6 being not important at all). The items were (nuances come from the translation): 
What is the best way for you to grasp the meaning of something in physics lessons and feel that you understand it?

(a) When the teacher talks about the phenomena

(b) When you see pictures of the phenomena

(c) When you are given diagrams and graphs relating to the phenomena

(d) When you are given a chance to have your own discussions (with each other) about the phenomena

(e) When you see the mathematics and calculations

(f) When you see animations or visualizations of the phenomenon

3. Interview-discussions with students in pairs, video, and audio recorded: The data collected from the video recordings and questionnaire (for the grounding research questions) was used to design the interview-discussion, in particular, for what representations and for what discussion themes would be introduced. We wanted the discussions to take place in an interactive-dialogic way and the information about the students' experiences with communitive practices in their wave physics course helped us to realize an interactive-dialogic environment. Furthermore, during the interviewdiscussions, different modes of representation that were used during the lectures were discussed; the students were asked about how the different representations helped afford their meaning making. Mathematical, pictorial, diagrammatic, and graphical representations were reproduced on cards to provide opportunities to point out any experienced critical details and to provide opportunities to make crosslinks to other representations. The discussion centered on the diagrams, graphs, and mathematics (i.e. mathematical formalism) modes of representations that the students experienced during their lectures. Part of these discussions led to the students' relating their viewpoints to everyday-life phenomena. This opened up discussions about a message-in-a-bottle animation that the students were shown during one of their lessons.

The participating students were invited to take part in interview-discussions in pairs. Eight interview-discussions with 15 students were conducted after the second lesson (one interview-discussion was done with one student). After listening to these interviewdiscussions repeatedly, areas of interest started to emerge. These areas were then transcribed verbatim and translated from Swedish into English.

\section{Results}

\section{Grounding research questions}

What Communicative Approaches Were Used? The teacher's communicative approaches were categorized, as shown in Table 1, using the Mortimer \& Scott (2003) communicative approach model described earlier. We have characterized Mortimer and Scott's categories to match our research context. These are described in Table 2. For example, we have characterized the authoritative-interactive communicative approach as "questions and answers."

During the first lesson, three of the four different communicative approaches were used. This lesson was an introduction to the course, and thus, many basic concepts were discussed with much of it derived from student input. The teaching approach used 
questions with good wait-times (interactive/authoritative) and then moved into more indepth discussions that were intended to bringing out the students' prior knowledge of wave phenomena (interactive/dialogic).

During the second lecture, the teaching content (see Table 2) contained much more mathematics representation (42 compared to $8.5 \%$ during the first lecture). The communicative approaches used then became much more traditional (noninteractive/authoritative).

\section{What modes of representation were used?}

The communication approaches and representation categories that were developed were independently verified by the authors with more than an $80 \%$ interrater reliability (cf. Stemler, 2004; see Table 3).

\section{TABLE 1}

Description of the communicative approaches

The interactive-authoritative
communicative approach is used when the
teacher initiates the conversation by a
question, searches for an answer, and
evaluates this answer. The discourse
pattern is typically I-R-E (initiation-
response-evaluation), and it is a question-
answering pattern that gives little
opportunity for the student to discuss
further, or give own questions to deepen
the discussion (we call this "questions and
answers" in Table 2).
The interactive communicative dialogic
approach is taken when the teacher opens
up for student ideas and gives time for
discussion. The discourse pattern is
typically I-R-P-R-P (initiation-response-
probing-response-probing). This is time-
consuming, but can be of great value for
students to put their experiences and
questions into the lecture (we call this
"probing" in Table 2).

The non-interactive-authoritative communicative approach is used when the teacher lectures and tells the students about the physics content, using different representations, and does not involve the student in the conversation. This approach is used to give information rapidly (we call this "lecturing" in Table 2).

The non-interactive-dialogic communicative approach is when the teacher reviews what ideas students have brought into the discussion and reasons around different views that can be taken. How different representations are used could be one example of reviewing alternative ways to look at a situation (we call this "reviewing" in Table 2).

The first lecture used $6 \%$ of the time for course information purposes (Management Talk). The rest of the lecture used representation modes that traditionally form part of any introductory wave physics course dealing with travelling waves. For both lessons, the most dominant mode used was the mode we have characterized as Pictures and Diagrams and Graphs. However, a large shift occurred in the second lecture from the Written Language mode to the Mathematics mode. 
Communicative approaches categorized in 20-s intervals during effective teaching used during lesson 1 and lesson 2

\begin{tabular}{lll}
\hline Communicative approaches & $\begin{array}{l}\text { Lesson 1 } \\
(\%)\end{array}$ & $\begin{array}{l}\text { Lesson 2 } \\
\text { (\%) }\end{array}$ \\
\hline The interactive-authoritative CA (questions and answers) & 19.6 & 0 \\
The non-interactive-authoritative CA ("lecturing”) & 70.7 & 100 \\
The interactive-dialogic CA (probing, elaborating, and & 9.8 & 0 \\
supporting) & 0 & 0 \\
The non-interactive-dialogic CA (reviewing) & 0 \\
\hline
\end{tabular}

$C A$ communicative approaches

TABLE 3

Modes of representations used during the first two lessons covering traveling waves

\begin{tabular}{lcc}
\hline Modes of representations (in \% of lesson time) & First lesson & Second lesson \\
\hline Written Language & 44.7 & 5.7 \\
Pictures, Diagrams and Graphs & 31.9 & 43.2 \\
Mathematics & 8.5 & 42 \\
Animations & 4.3 & 2.3 \\
Demonstrations of Conceptual Principles & 4.3 & 5.7 \\
Management Talk & 6.4 & 1.1 \\
\hline
\end{tabular}

\section{What was the trend in students' views of what different representations are preferable for meaning making?}

Figure 6 shows all options that emerged from the questionnaire that was completed by 62 (out of 70) students in the course. The students ranked the best way to grasp the meaning and to gain understanding was when their teacher used the mode Teacher Talk, to describe the content and related phenomena $(17 / 62=27 \%)$ and when they had opportunities to have discussions with their peers, Peer Talk, about the phenomena $(17 / 60=28 \%)$; when they were able to solve problems mathematically, Calculations $(15 / 59=25 \%)$; and when they were shown animations, Animations $(17 / 58=29 \%)$. Very few students ranked the mode Diagram and Graphs highly $(3 / 55=5 \%)$. In the second and third rankings, the results show Diagrams and Graphs to again be the lowest ranked.

An ANOVA Friedman test (non-parametric test for testing the difference between several related samples (Siegel \& Castellan, 1988) was conducted on the questionnaire results (see Table 4). The test shows significantly (p G o.001) that at least two of the variables differ from each other. The multiple comparisons show from the mean rank that the categories Peer Talk and Teacher Talk are the most preferable, followed by Animations, Pictures, Calculations, and finally Diagram and Graphs. Here it can be seen that Teacher Talk and Animations significantly differ from Calculations and Diagram and Graphs and 
how this last category differs from all the other categories. Peer Talk is significantly different from Calculations, Diagram and Graphs, and from Pictures.

All in all, the communicative categories or the modes of representations originating from the broad category of Spoken Language are ranked significantly more preferably than all the other categories.

TABLE 4

Friedman multiple comparisons test on questionnaire given before the first lesson (minimum required difference of mean rank 0.6098)

\begin{tabular}{lll}
\hline Variable & Mean rank & Different $(p<0.05)$ from variable $n r$ \\
\hline (1) Teacher Talk & 2.9737 & (3) (5) \\
(2) Pictures & 3.5175 & (3) (4) \\
(3) Diagram and Graphs & 4.9386 & (1) (2) (4) (5) (6) \\
(4) Peer Talk & 2.8860 & (2) (3) (5) \\
(5) Calculations & 3.6754 & (1) (3) (4) (6) \\
(6) Animations & 3.0088 & (3) (5) \\
\hline
\end{tabular}

The representations that are dynamic are more preferable than those that are static, and it is clear that the students rank Diagram and Graphs as significantly least preferable (a category that is troublesome for the students).

When this questionnaire was given during the last lesson in the course, the number of students was only 37. However, our aim was to capture the nature of the general trend of representation preference said before we had no possibility to identify individual students (see Figure 7).

The result is consistent in the sense that the Friedman test shows significance (p G o.001) in that at least one category is different from the others and that in the ranking of categories, Peer Talk, Animations, and Teacher Talk are the three categories that are still the highest ranked. However, the differences between how the categories differ between themselves show significance only for one category, namely Diagrams and Graphs (see Table 5). 


\section{TABLE 5}

Friedman multiple comparisons test on questionnaire given during the last lesson in the course (minimum required difference of mean rank 0.8084 )

\section{Variable}

(1) Teacher Talk

(2) Pictures

(3) Diagrams and Graphs

(4) Peer Talk

(5) Calculations

(6) Animations
Mean rank

3.1667

3.4861

4.8333

2.9583

3.4583

3.0972

Different $(p<0.05)$ from variable $n r$

(3)

(1) (2) (4) (5) (6)

(3)

(3)

(3)

Principal research question: how did the students discuss the representations in relation to making meaning from some of the basic building block concepts for the course?

Students Try to Become Fluent in Different Modes of the Disciplinary Discourse A general aim of teaching physics can be portrayed as wanting students to become discursively fluent in the disciplinary discourse. Part of this path of learning is characterized by what Airey \& Linder (2009, p. 34) describe as "discourse imitation"-a repetitive practice to obtain and acquire, for example, the ability to solve problems in textbooks. Many students meet after the lectures and discuss how to solve problems. They help each other by explaining to each other, often using their own descriptions (in contrast to what the teacher used). They describe how they explain in ways that they themselves have found useful for meaning making, for example (taken from the interview-discussion):

INTERVIEWER: Is it the problem-solving ...?

STUDENT 3: Yes, it is ... of course. It can be that someone has understood a part very good, and then you can with words, other words, than the teacher uses, saying that this is how it actually is talking at the same time) ....seated around the homework assignments you should...

STUDENT 3: solve ...

STUDENT 4: Well, not that you ask each other-What did you think of today's lecture? No...

STUDENT 3: No, we solve the problems, which are to solve, and talk about them.

The students need to engage among themselves and with their teacher in a multifaceted discourse, bridging disciplinary modes of representation and their common sense notions about how the world works. Ideas need to be tested and contested, and all demand equal dialogic status. This is a collage to be certain, one we see as being "carnivalesque" (Bakhtin, 1930). Engaging with the disciplinary discourse ultimately leads to meaning making, and by putting together the different fragments of their sense-making, students stand to gain a more confident and informed approach. Through giving consideration to everyday life wave phenomena, students are able to open up the possible affordances of 
representations that they are not familiar with, for example, waves in diagrams, pictures, and equations. For example, see the next exemplar involving discussion around a message-in-a-bottle.

Students' Meaning Making from an Everyday-Life Example-Message-in-a-Bottle During the interview-discussions, one of the things that the students discussed was the representation used during lesson 1 about a wave in a string (Figure 3). They were also asked for their understanding of the propagation of a message-in-a-bottle (at sea) example given to them in the lesson.

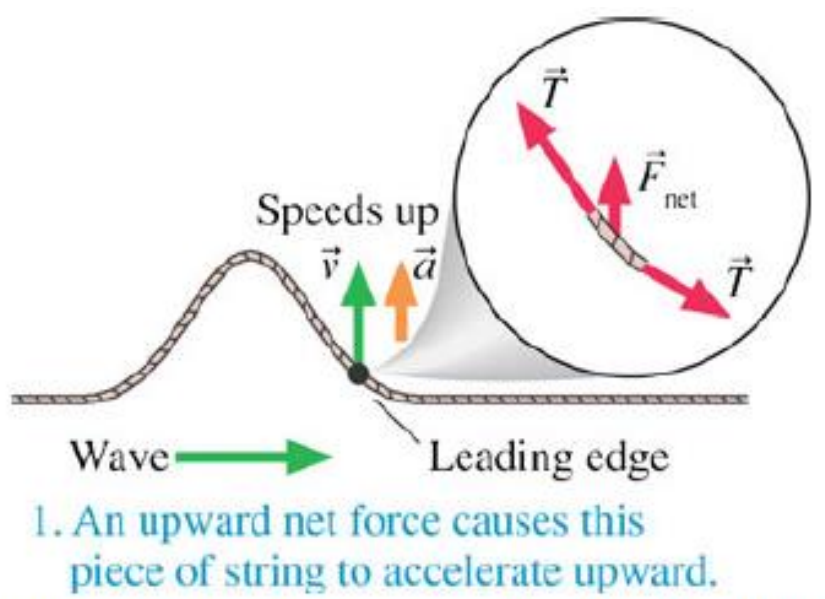

Figure 3. Representation of wave pulse forces on a string (extracted from Figure 20.2, Knight, 2004)

The students are very positive about the relation between this wave physics representation and how the teacher built the discussion on their already completed mechanics course. They express how meaning making in the disciplinary discourse is supported by the way the teacher provides scaffolding from one representation (net force acting on a particle in a rope) to another (travelling waves).

STUDENT 4: We liked it actually. Really. I had a little different idea of how it happened, but when [the teacher] got it...these resulting tension forces $\mathrm{T}$, and the resultant going up, it was pretty good for the mechanics that we've just done, and ...

STUDENT 3: No, that's true.

STUDENT 4:... And when [the teacher] showed up at the white-board, yes, that's right so ... a new way of thinking, it was actually, it was quite interesting, I liked these images.

When the students are challenged by the question of how they see a message-in-a-bottle at sea from a wave physics conceptualization, they get confused. They try to see the bottle as a particle in a string and explore the conclusion that, in that case, the bottle would only move up and down and never move sideways, as a particle in the string does. They also explore how a horizontal external force would be needed to propagate the bottle sideways, which are not in the particle-in-string representation.

STUDENT 3: Then it would arise different forces, which this picture disregards. The bottle would only move up and down, according to this picture. Then it needs to be other forces that exist here...the wind blows, or...This isn't enough to explain. 
STUDENT 4: no ... no.

STUDENT 3: According to this [representation], the bottle wouldn't move after you've thrown it into the sea, it says this. Yes, in my world. Then you need to see the bottle as a particle.

STUDENT 4: But, it's not a part of the rope. So it's something else, you do get that the wave transports energy, so the bottle would move after a while, both up and down and sideways.

STUDENT 3: But it's not the wave that moves ...

In so doing, they suggest that the bottle is also acted on by the wind. This example also illustrates how Peer Talk affords new meaning making of representations. How waterwaves differ from mechanical waves is not addressed, however. Next, two other students grapple with finding a concise explanation using many physics concepts, which in itself can be seen as part of the process of achieving discursive fluency.

INTERVIEWER: If we throw in a message in a bottle in the lake, so we hope that it will come ashore or so. How is it then?

STUDENT 2: That's when the rapid-flowing water, which ... you may of course get a wave motion and reflection outwards, but the wave motion is in some way triggered by solar or wind energy, which is also a form of solar energy...all energy comes from the sun if you say, that makes the movement. The energy is taken up in the bottle, then, well it's not absorbed by the bottle, but it is used by the bottle when it is moving. As I see it. But it might get really weird.

STUDENT 1: That was too complicated, I think. It is mostly that the bottle is a unique object; it is of course independent of the wave, it moved with the wave, but is not part of the wave movement. The bottle simply is moved by the ...(interrupted by Student 2 and they're speaking all at once, partly inaudible)

STUDENT 2: ... it is pushed here by ...

STUDENT 1: It's not a particle of the wave that pops up and down ...

INTERVIEWER: What is the difference then? What is the difference in being a water molecule or to be a bottle ... [interrupted]

STUDENT 1: It is not part of the wave motion.

STUDENT 2: The water-molecule is ... if you take the rope here, of course it has its limits, it is of course in particular pattern, it moves not there ... but if you put something up on the rope and then flicks to fly off the course as well...

STUDENT 2: ... but it gets of course part of the force, it must of course get part of the resultant. It receives part of the resultant, it gets acceleration and speed, but of course it has nothing to do with the wave. It is another object, it is some of Newton laws, therefore, thus the forces ... they are acting towards each other somehow ...

We can see in the message-in-a-bottle discussions about the rope-wave and water wave representations, together with the interviewer's questions, interactions with the students' prior conceptions about waves. What is interesting to see is how the discussions bring the students to a point where they can start to show understanding of the role of representations in affording understanding-a "talk this out" in exploratory talks (Barnes\&Todds, 1995). A question that arises from the way meaning making emerged through the Peer Talk mode of representation seen in these illustrative examples is: if this 
kind of insight should not be an essential part of lesson planning and course design? In other words, meaning making should not be taken to be an inherent quality of representations themselves.

\section{Students' discussions of animations in the teacher's presentation}

One result from the questionnaires indicates that Animations are highly ranked. The students expect and find Animations to be valuable for their meaning making of the content of learning physics (basic building block concepts). In the interview-discussions, the students also talk about the richness of Animations. They emphasize that the technology for the production of good modes of Animation now exists and they would like to have more of it; they particularly liked to be able to see things in "moving form" because that reduces the risk for misunderstandings.

STUDENT 3:... Well, there was nothing wrong with the picture, but why do you not make it move? Now when the technology already exists! I would think it would make it even clearer if it was moving.

INTERVIEWER: Do you like animations at all?

STUDENT 3: YES!. It's easier than a static picture, for you can imagine wrong. And you need to know that the wave comes from that way (pointing), and you need to see that arrow ...

STUDENT 4: Though in this particular example (showing a pulse with one hand) you know how it goes ...

STUDENT 3:... Though it might not all do ...

STUDENT 3: I think it would be better if it moved, and then one would recognize it as a standstill after that.

STUDENT 4: Oh sure, it might be good.

STUDENT 3: Since the technology already exists ...it's not harder to get that to move about than to do four pictures of it ... I think ... or do I know ...

Animations are seen to have the potential for extending the meaning making, especially when the content depends on student ability to make meaning of motion, but "students need also help attending to the relevant parts of an animation" (Dancy \& Beichner, 2006, p. 1).

\section{Students' discussions of diagrams and graphs in the teacher's presentation}

The students' explanations of the diagram in Figure 4 confirmed their confusion with symbols and letters used during instruction. The students discuss the meaning of the symbol D in the figure, and at first, they confuse D with the sign for derivative. They express that, for them, amplitude is connected to the symbol A, or even better y as in their mathematics. This type of discussion is more easily facilitated in Peer Talk than in a traditional large-class environment (cf. Mazur, 2009).

STUDENT 2: What's the big D for something?

STUDENT 1: Isn't it the propagation of light wave or sound wave or the wave at any time, at the time $t$ ? It's wavelength.

STUDENT 2: It's not at the time $\mathrm{t}$, for $\mathrm{t}$ says $\mathrm{t}=\mathrm{o}$ here

STUDENT 1: Oh, yes, it is a snapshot. 
STUDENT 2: A snapshot yes. As you can see what it looks like yes.

INTERVIEWER: You said it was a snapshot when time was zero. But you said something more, what does D means to you?

STUDENT 1: Yes, good question. D must surely be the derivative of ...

STUDENT 2: No. No.

STUDENT 1: ... isn't it ...

STUDENT 2: No, I do not think so. There you have the amplitude (isn't it called amplitude?)

STUDENT 1: Yes, amplitude.

INTERVIEWER: What is amplitude?

STUDENT 2: It's the height.

STUDENT 1: It's + A

STUDENT 2: $\quad \mathrm{D}$ what can it be ... the length ...

INTERVIEWER: If you could change the $\mathrm{D}$ to another letter, what would it be? STUDENT 2: Yes, logically there would be a y.

STUDENT 1: Yes, we'll say that!

INTERVIEWER: D is displacement. It might as well have been y. So it's a little funny that they are big $\mathrm{D}$, as we use $\mathrm{D}$ as a derivative-symbol.

STUDENT 1: Well, then it's the same D that is here (pointing to the figure, see Fig. 4.) I'd have probably better understood if it stood for y instead.

STUDENT 2: No, it does not matter.

STUDENT 1: Well, for me it does.

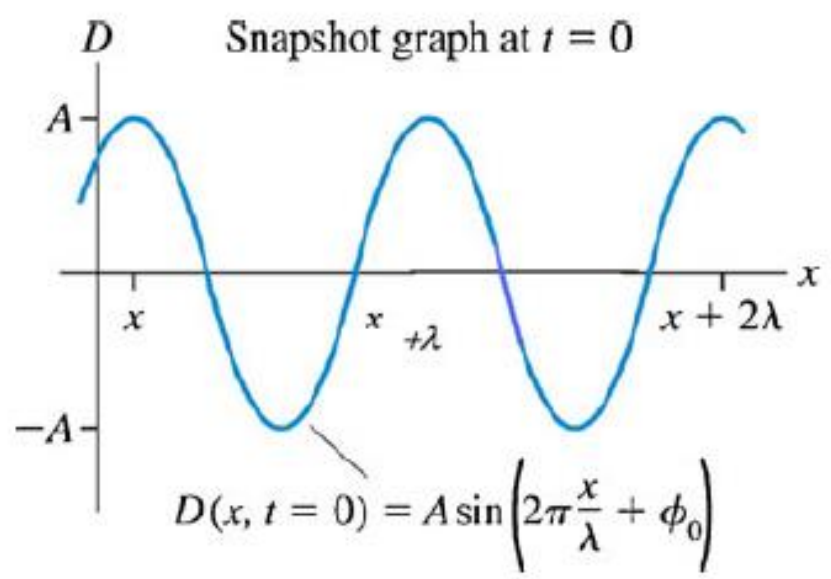

Figure 4. Graphs of the wave equation as a snapshot at $t=0$ (extracted from Figure 20.16 in Knight, 2004)

This exemplar discussion of a Diagram and Graph mode of representation illustrates the difficulties students have in affording meaning from this mode. In this case, the use of abbreviations is a source of their difficulties, which could have been minimized if variable names were used instead of symbols.

\section{Students' discussions on mathematical representations}

During the lecture, the teacher showed the general wave equation (Figure 5) and pointed out its generalizability across different wave forms. The students in the next illustrative exemplar (from the interview-discussions) try to figure out what a second derivative could mean in a physical and in a mathematical sense for the general wave equation (Figure 5). 


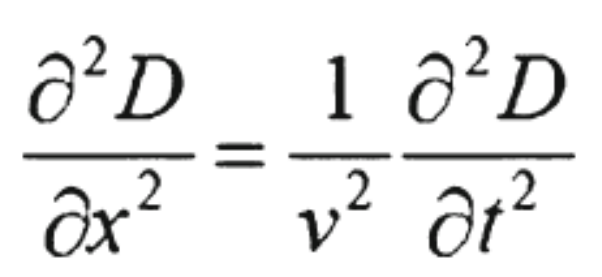

Figure 5. The general wave equation

They try to discuss the wave equation from a mathematical view, but do not have the ability to say anything about how it relates to physics phenomena. To reach fluency in physics as disciplinary discourse, they need to learn to see how mathematics is used to describe physics phenomena, a connection that these students cannot see.

STUDENT 3: It's pure mathematics. Some have read more mathematics, and I can imagine that when they are better to identify with the second derivative ...

STUDENT 4: But what is the second derivative of the elongation then ...?

STUDENT 3: Yes, what is the derivative of the sine, cosine is negative, and then you derives once more ...

STUDENT 4: Yes, but what is purely physical about it?

STUDENT 3: Yes, the first derivative is the slope at a certain point, and the second derivative is of course ... what is it now ... if it increases or decreases ...

STUDENT 4: But if we decide that it is to determine the maximum, so the first derivative gives a maximum elongation if we were to equate it with zero ... to determine ... then we will have a value and then we do not know ... if we do not have the picture as to what it is for something. Then we use it when it gets this or that. (Showing with his hands)

This relation between displacement, position, time, and speed of the wave propagation is not familiar at all to these students. They seem to refer to one-dimensional functions from their mathematics course. In this example, they are unlikely to be able to resolve the problem through Peer Talk-a constellation of modes is needed (cf. Airey \& Linder, 2009).

\section{Discussion}

The case study that we have described and illustrated has been about the meaning making associated with different disciplinary representations in an undergraduate physics learning context. A number of interesting aspects emerge. The first is that representations do not, in themselves, necessarily enable a range of meanings. The second is that it seems that representation affordance is critically related to how the representations get situated in a learning environment. Finally, because of the way the students called on different representations in their interview-discussions and because the questionnaire that they answered showed that they had experienced different meaning making aspects from different forms of representations and thus had different representation preferences, our analysis can be seen to support the Airey \& Linder (2009, p. 27) conjecture that "fluency in a critical constellation of modes of disciplinary discourse may be a necessary (though not always sufficient) condition for gaining meaningful holistic access to disciplinary ways of knowing." 


\section{Representations do not in themselves necessarily enable a range of meanings}

In our result, we have illustrated the nature of affordances that emerged across different modes of representations, namely Peer Talk, Animations, Diagram and Graphs, and Mathematics. These examples clearly show how different modes of representation all have aspects of meaning making that they cannot afford, which is expressed by the level of preference that the students assigned to them in the before and after lessons questionnaire that we have reported on (see Figures 6 and 7). In relation to the outcomes of the questionnaire and the illustrative transcript examples that we have provided, we find the Airey \& Linder (2009, p. 38) suggestion "that students will need to become fluent in a given mode of disciplinary discourse before they are able to experience the facets of the particular disciplinary way of knowing that that mode affords" to be highly relevant. We argue in this article that a very important part of becoming fluent in any mode of representation is through Peer Talk in group discussions.

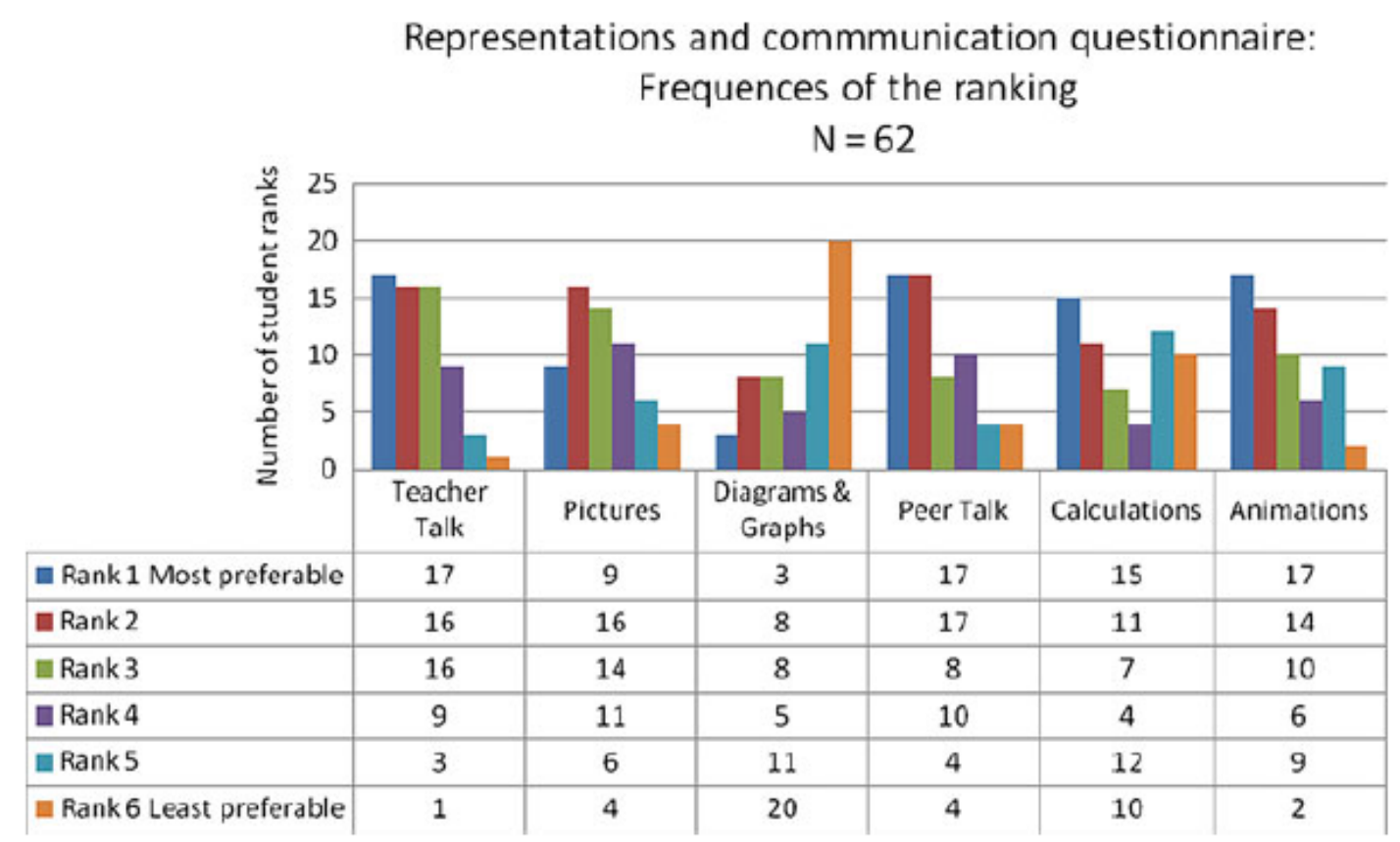

Figure 6. Students preferences and ranking of representations and communication in a questionnaire given before the first lesson 


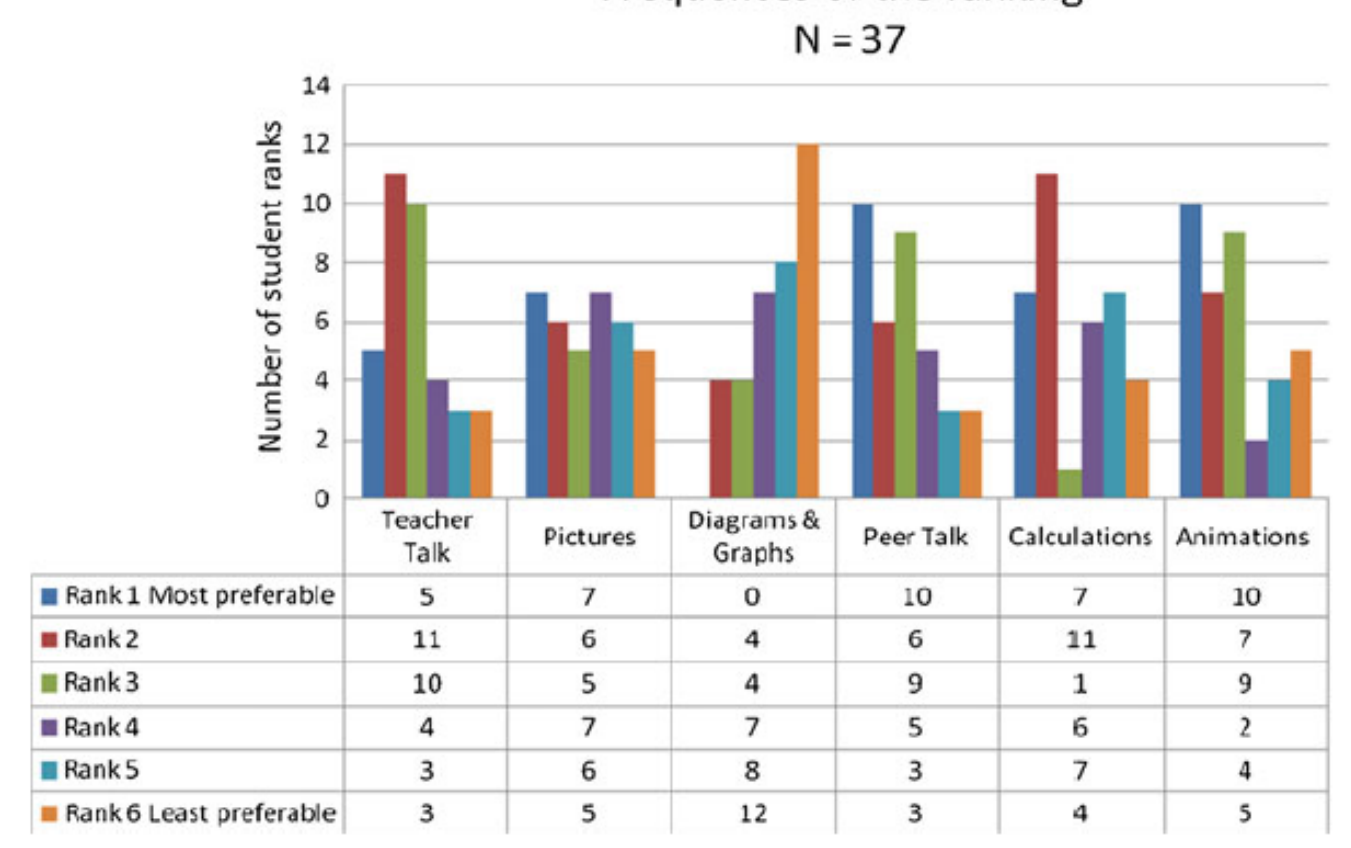

Figure 7. Students preferences and ranking of representations and communication in a questionnaire given before the last lesson

\section{Representation affordance is critically related to how representations get situated in a learning environment}

Our analysis of the communicative approaches used during the lessons (Table 2) shows how, during the first lesson, the teacher took an interactive-dialogic communicative approach to wave physics content. Comparison between the first and second lesson shows that the teacher invited communication much more in the first lesson than in the second lesson, which mainly dealt with mathematical procedures and modeling. In other words, during the second lesson, the teacher used more of an authoritative/non-interactive communicative approach. We argue that even for lessons with large mathematical content, Peer Talk is an essential representation mode. When the students discuss topics with each other, we see that everyday examples foster critical thinking, physics reasoning, and meaning making. When the students compared the mechanical wave in a string with the every-day life situation of a message-in-a-bottle in the sea, Peer Talk facilitated an affordance that allowed differences between water-waves and waves in a string to emerge (one pair of the interviewed students even outlined an experimental setup to investigate if a bottle was propagated horizontally by wind or not).

Teacher's awareness of different communicative approaches and treating students as partners in staging the lessons could make a difference to how learning gets afforded in physics courses. In our illustrative examples, we see how the educational setting provides a framing for the students to feel "safe enough" to reveal their meaning making and to "admit" to the things they have not understood. But they also seem to be aware that there are different ways of seeing things, as expressed for example by reference to "my world" of meaning making in trying to reconcile what is reasonable about another way of seeing something (see the message-in-a-bottle illustrative transcript, student 3). 


\section{Constellation of modes of disciplinary discourse necessary but not always sufficient}

These data, particularly the discussion about the message-in-a-bottle, show how the students involved in this discussion are framing the problem in different ways by using different representations. At the same time, the questionnaires showed that the students rank, for example, Peer Talk and Animations relatively highly for the possible meaning making that they present for them. One student discussed how he had interpreted a diagram differently than the teacher did, how he compared his own understanding with that of the teacher, and how he learned from doing this. Yet, collectively the representation diversity that they were exposed to was not sufficient for the students to make meaning. For example, a representation that was missing was one that easily facilitated meaning making for contextually appropriate abbreviations of variables in relation to their intended concepts. An illustration of this being the mismatches between "D" used for derivative and "D" used for displacement that we saw emerge in one of the illustrative transcripts.

\section{Pedagogical comments}

As our study progressed, we increasingly began to build an appreciation of how the research processes that we were going through could be seen as a model for creating pedagogical resources for courses such as the one we used for our case study. In a certain sense, a claim could be made that it is obvious that Peer Talk is a critical mode of representation. But we saw how it could not be sufficient in itself. We, as physics teachers, need to attain a much deeper and wider set of insights into what meaning a representation is able/unable to afford and thus what constellations we need to incorporate into the learning experience for our students. If our educational aims are embedded in achieving fluency in disciplinary discourse, we need to focus activities in a physics course around modes of representation that foster a pedagogically rich exchange of knowing in an environment where students "feel safe" enough to engage with the representations in an open and honest way.

Physics teaching practice at the university level needs more interactive-dialogic communication in order to give the students feedback on the questions they address and, therefore, more "voice" in their learning. In order to come to understand the physics concepts, students need also to learn about their pathways towards disciplinary fluency in the physics disciplinary discourse-when they connect deeply with the subject matter in a way that necessarily requires new ways of thinking, new perspectives, and often a new "metaphysics," they feel in control of their learning. Our study has illustrated student discussions about using the Peer Talk modality, and the transcriptions of the interview-discussions with the participating students have demonstrated how students can benefit from using Peer Talk to engage with other modalities such as Animations, Mathematics, and Diagrams and Graphs. We have shown in the illustrative transcripts how they sort through their prior understandings and experiences in the world in order to make sense and bring meaning to the new physics content with which they are being presented.

Overall, our analysis for all the research questions raises a set of issues that have relevance for teaching physics. While these issues may not all directly emerge as part of answers 
to the research questions, they do provide an additional research-informed resource list for undergraduate physics teachers. These are awareness of the significance of:

- Peer Talk-to make it possible for students to "talk about" new concepts soon after these concepts are introduced and to situate these in other modes of representation that can potentially optimize the intended meaning makings

- Using a variety of communicative approaches while noting the benefits of using more of the dialogic approach for students to feel included in the physics disciplinary discourse and to help them to proceed towards disciplinary fluency

- Animations as a mode that can potentially afford different and important aspects of meaning making of physics concepts, especially when motion is an essential attribute of the concept

- Students learning to contextually interpret variable symbols

- The mode we called Diagram and Graphs as a complex mode for introductory students to engage with and thus additional time and effort is going to be needed for these engagements

- Being sensitive to when Peer Talk is being productive and when it needs fruitful intervention

- Gaining further insight about students as learners from their Peer Talk

\section{Further research}

The students described how they found Animations to be particularly useful in affording learning. This seems to be a promising area for further research, especially in terms of how animations can "bring to life" concepts and understandings in physics that might otherwise be near impossible to share knowledge across levels of physics education, such as astronomical events of proportions that are difficult to visualize, or time-lapse representations of physical processes, or theoretical modeling of some abstract system such as general relativity. The dimensions of space-time by multi-dimensional events need to be given more attention in physics teaching. Another useful thrust for further research would be to use student reflections of the type obtained for our case study in order to take a closer look at how to optimally use different communicative approaches in relation to different representations and their multimodal settings.

\section{Conclusion}

Students benefit from discussions about physics phenomena, not only in terms of making meaning by "talking through" their understandings of events and their theoretical significance but also in terms of improving their disciplinary discourse skills. By formulating their observations, explanations, and thought experiments, students frame and reframe (Schön, 1983, 1987) the disciplinary representations that are at hand, talking their way from their everyday, often informal and literal notions about the world, through to the more refined, idealized, and conceptually laden understandings that lie hidden in the multimodality of, for example, Diagrams and Graphs and Mathematics. Understandings are simply not inherent in the representations themselves, lying there waiting to be uncovered, consumed, or digested; they are formed through a reflective journey that might best be understood as a "carnival" shifting from one modality to 
another, one frame to the next, as ideas are fleshed out through thought experiments that often check the merits and the limits of one set of ideas over another.

Just as we see physics undergraduate students in Peer Talk trying to sort out their understandings, we as physics teachers and researchers also need, as teachers, our own Peer Talk to help better understand how to optimize learning possibilities for our students. In the illustrative interview-discussion exemplars, we saw a dynamic exchange involving the articulation and formulation of meaning making, as though this meaning making was experienced through a crystallization-like process that required intricate engagement with representations. We argue that it is critically important to understand our students as learners in this regard in order to be able to share physics knowing with them in an optimal way.

\section{Acknowledgments}

The authors are grateful to the teacher and students that participated and shared their time. We thank the two anonymous reviewers for their useful comments on this article. We are also grateful to Anne Linder for her engagement and rigorous correction suggestions of the article. The research was financially supported by the Swedish Research Council. 


\section{References}

Airey, J. (2009). Science, language and literacy. Case studies of learning in Swedish University Physics. Acta Universitatis Upsaliensis. Uppsala dissertations from the Faculty of Science and Technology 81. Uppsala Retrieved 2009-04-27, from http://publications.uu.se/theses/abstract.xsql?dbid=9547.

Airey, J. \& Linder, C. (2009). A disciplinary discourse perspective on university science learning: Achieving fluency in a critical constellation of modes. Journal of Research in Science Teaching, 46(1), 27-49.

Bakhtin, M. M. (1930, 1981, 2010). The dialogic imagination: Four essays by M.M

Bakhtin. In M. Holqvist (Ed.) Translated by C. Emerson and M. Holquist. Austin, TX: University of Texas Press.

Barnes, D. (1977). Communication and learning in small groups. London: Routledge \& Kegan Paul Ltd.

Barnes, D. \& Todd, F. (1995). Communication and learning revisited: Making meaning through talk. Portsmouth, NH: Boynton/Cook.

Blumer, H. (1969, 1986). Symbolic interactionism: Perspective and method. Berkeley, CA: University of California Press.

Dancy, M. H. \& Beichner, R. (2006). Impact on animation on assessment of conceptual understanding in physics. Physics Review Special Topics-Physics Education Research, 2(010104), 1-6.

Deslauriers, L., Schelew, E. \& Wieman, C. (2011). Improved learning in a large enrollment physics lesson. Science, 332, 862-864.

Dewey, J. (1938, 1997). Experience \& Education. New York: Touchstone.

Enghag, M., Gustafsson, P. \& Jonsson, G. (2007). From everyday life experiences to physics understanding occurring in small group work with context rich problems during introductory physics work at university. Research in Science Education, 37, $449-467$.

Erickson, G. (2007). In the path of Linnaeus: The development and nurturing of science educators for a complex world. In C. Linder, L. Östman, D. Roberts, P.-O. Wickman,

G. Erickson \& A. MacKinnon (Eds.), Exploring the landscape of scientific literacy (The Teaching and Learning in Science Series, pp. 207-222). New York: Routledge.

Froyd, J. E. (2008). White paper on promising practices in undergraduate STEM education [Commissioned paper for the Evidence on Promising Practices in Undergraduate Science, Technology, Engineering, and Mathematics (STEM) Education Project, The National Academies Board on Science Education, 2008]. www7.nationalacademies.org/bose/Froyd_Promising_Practices_CommissionedPa per.pdf.

Gautreau, R. \& Novemsky, L. (1997). Concepts first: A small group approach to physics learning. American Journal of Physics, 65(5), 418-428.

Hake, R. (1998). Interactive-engagement versus traditional methods: A six-thousand student survey of mechanics test data for introductory physics courses. American Journal of Physics, 66(1), 64-74.

Knight, R. D. (2004). Physics for scientists and engineers with modern physics. A strategic approach. San Francisco: Pearson Addison Wesley. 
Kohl, P. B. \& Finkelstein, N. D. (2006). Effects of representation on students solving physics problems: A fine-grained characterization. Physical Review Special Topics-Physics Education Research, 2, 010106.

Kress, G., Jewitt, C., Ogborn, J. \& Tsatsarelis, C. (2001). Multimodal teaching and learning: The rhetorics of the science classroom. London: Continuum.

Mazur, E. (1997). Peer instruction: A user's manual. Series in educational innovation. Upper Saddle River, NJ: Prentice Hall.

Mazur, E. (2007). Interactive teaching-promoting better learning using peer instruction and just-in time teaching. Cambridge, MA: The Derek Bok Center for Teaching and Learning, Harvard University in Association with Spectrum Media and Pearson Education.

Mazur, E. (2009). Farewell, lecture? Science, 323, 50-51.

Mercer, N. (1995). The guided construction of knowledge: Talk amongst teachers and learners. Clevedon, UK: Multilingual Matters.

Mercer, N. (2000). Words and minds: How we use language to think together. London: Routledge.

Mortimer, E. F. \& Scott, P. H. (2003). Meaning making in secondary science classrooms. Buckingham, UK: Open University Press.

Rimmele, R. (2002). Videograph. Kiel: IPN-Leibniz Institute for Science Education.

Schön, D. (1978). Generative metaphor: A perspective on problem setting in social policy. In A. Ortony (Ed.), Metaphor and thought. Cambridge, UK: Cambridge University Press.

Schön, D. (1983). The reflective practitioner: How professionals think in action. New York: Basic Books.

Schön, D. (1987). Educating the reflective practitioner. San Francisco: Jossey-Bass.

Siegel, S. \& Castellan, N. J. J. (Eds.). (1988). Nonparametric statistics for the behavioural sciences. New York: McGraw-Hill

Stemler, S. E. (2004). A comparison of consensus, consistency, and measurement approaches to estimating interrater reliability. Practical Assessment, Research\& Evaluation, 9(4).

Van Heuvelen, A. (1991). Overview, case study physics. American Journal of Physics, 59 (10), 898-907.

Van Heuvelen, A. \& Etkina, E. (2006). The physics active learning guide. San Francisco: Pearson. 